\title{
The International Society of Pharmacovigilance (ISoP) Special Interest Group on Herbal and Traditional Medicines: Towards Progress in Pharmacovigilance for Herbal and Traditional Medicines and Other "Natural Health" Products
}

\author{
Joanne Barnes ${ }^{1}$ (D) \\ Published online: 23 April 2020 \\ (c) Springer Nature Switzerland AG 2020
}

\section{Introduction}

Herbal medicines, or herbal medicinal products, cover manufactured products containing herbal ingredients, and simple preparations of herbal substances. Most, if not all, traditional medical systems, including traditional Chinese medicine (China), Ayurvedic medicine (Indian subcontinent), Aboriginal medicine (Australia), te rongoā Māori (New Zealand), and many others, include the use of herbal ingredients (i.e. substances originating from plants); many traditional (indigenous) medicines also include ingredients from other sources (e.g. animals, insects, minerals).

Herbal and traditional medicines (H\&TMs) are a popular, sometimes the only, healthcare choice among people worldwide. In Western countries, out-of-pocket expenditure on herbal medicines and other 'natural health' products (NHPs), and on consultations with H\&TM practitioners, is substantial [1-8]. Market data indicate large sales volumes: for the year 2018, in the USA alone, estimated retail sales of "herbal supplements" totaled more than \$US8.84 billion, an increase of almost $10 \%$ over the previous year [9]. Many consumers of these types of products use them concurrently with conventional prescription medicines [10], which can lead to serious drug interactions. In many low- to middleincome countries, a substantial proportion of the population relies on H\&TMs and traditional healers as their main, or only, source of primary healthcare [11].

Joanne Barnes

j.barnes@auckland.ac.nz

International Society of Pharmacovigilance Herbal and Traditional Medicines Special Interest Group, School of Pharmacy, Faculty of Medical and Health Sciences, University of Auckland, Private Bag 92019, Auckland 1142, New Zealand
The need to improve pharmacovigilance for H\&TMs and other NHPs is recognized internationally, not least because the use of these types of products is highly prevalent and because safety concerns associated with their use continue to emerge. For example, in recent years, signals (i.e. a causal relationship has not necessarily been established) of hepatotoxicity associated with black cohosh (Actaea racemosa $\mathrm{L}$.) root extracts [12], green tea (Camellia sinensis (L.) Kuntze) leaf extracts [13], and a supercritical carbon-dioxide extract of Artemisia aпnиa L. in grapeseed oil [14] have emerged in different countries.

Detection of signals of safety concerns associated with H\&TMs continues to rely almost solely on analysis and assessment of spontaneous reports of suspected adverse drug reactions (ADRs) associated with the use of these types of products submitted by health professionals and the general public. The limitations of spontaneous reporting, and the unique and additional challenges in pharmacovigilance for H\&TMs, are well-documented, but progress toward resolving them has been slow. Key international organizations have supported the development of pharmacovigilance practices for H\&TMs. For example, the World Health Organization (WHO) published guidelines on safety monitoring and pharmacovigilance for herbal medicines [15]. Also, the Uppsala Monitoring Centre (UMC) launched a traditional medicines programme to stimulate reporting for these products and developed the herbal anatomical therapeutic chemical (ATC) classification system [16], which has a structure consistent with that of the regular ATC system and provides a unique framework for the nomenclature and therapeutic classification of herbal substances and combinations of herbal ingredients.

The International Society of Pharmacovigilance (ISoP) has also focused attention on this topic. Pharmacovigilance for H\&TMs has featured at ISoP annual conferences for 
many years, including in plenary and parallel sessions. Further, ISoP working groups have been mindful of the need to include a herbal- medicines perspective in their work. For example, the International Society for Pharmacoepidemiology (ISPE) initiated a venture, supported by ISoP, that was tasked with preparing guidelines for the submission of reports of suspected ADRs to journals. This venture included an ISoP member with herbal medicines expertise, and the resulting guidelines-approved by both ISoP and ISPE-included reference to some of the additional items of information required for comprehensive literature reports of ADRs associated with herbal medicines [17].

\section{Formation and Membership of the International Society of Pharmacovigilance Special Interest Group (SIG) on Herbal and Traditional Medicines (H\&TMs)}

Against this background, in 2016, the new ISoP Executive Committee encouraged the creation and development of a new special interest group (SIG) in ISoP dedicated to exploring issues relating to the safety and pharmacovigilance of H\&TMs. The H\&TMs SIG was formally launched at the 17th annual meeting of ISoP, held in Liverpool, UK, in October 2017. The conference also featured a plenary session on pharmacovigilance for H\&TMs, which included a keynote lecture "Pharmacovigilance for herbal and traditional medicines: towards solutions and innovations" by Professor Phil Routledge, then Clinical Director of the All Wales Therapeutics \& Toxicology Centre, Wales, and Chair of the Committee on Herbal Medicinal Products, Medicines and Healthcare products Regulatory Agency (MHRA), UK.

Membership of the H\&TMs SIG is diverse in several ways. As reported at the 20th annual meeting of ISoP, held in Bogota, Colombia, in October 2019, the H\&TMs SIG included 22 members from 14 countries by the end of 2019. Members of the H\&TMs SIG have specific interests in H\&TMs in the broadest sense, including marketed commercial herbal medicinal products as well as all types of traditional herbal and indigenous medicines and other natural products used in healthcare. Members are employed in a range of pharmacovigilance settings, including national pharmacovigilance centers, medicines' regulatory agencies, academic institutions, and the herbal and pharmaceutical industries. Collectively, members bring a range of skills, expertise and experience across H\&TMs and pharmacovigilance; thus, the H\&TMs SIG is well-placed to advance the topic at a global level and in ways that are impactful, not least for users of H\&TMs.

Current members of ISoP with an interest in H\&TMs are invited to join the SIG. The group is keen to attract members from different continents and hopes to achieve strong representation from countries in which H\&TMs are an important part of healthcare, either locally for individuals, or as part of an organized health system. The H\&TMs SIG welcomes members with expertise in the chemistry, clinical pharmacology, manufacture, regulation, practice and, of course, pharmacovigilance of herbal medicines, including in relation to the many different traditional medicine systems, such as Ayurvedic medicine, traditional Chinese medicine and others. The SIG also welcomes members who have expertise in other areas of pharmacovigilance, including specific methods or therapeutic areas, and who are interested in exploring the interface of these with H\&TMs. However, it is not necessary to have particular expertise or experience in H\&TMs to join the SIG, and ISoP members with an interest in this topic are welcomed. If you would like to join the ISoP H\&TMs SIG, or have questions, please contact Associate Professor Jo Barnes by email (administration@ @isoponline.org).

\section{H\&TMs SIG: Aims and Objectives}

The overall aims of the H\&TMs SIG are to provide a focal point for ISoP members interested in H\&TMs and other NHPs to share and provide information on relevant issues and developments, and to support and promote progress in pharmacovigilance for these types of products and preparations. The group aims to share news items, research findings, regulatory actions and other information on herbal medicines issues that have been identified worldwide, including signals of safety concerns associated with herbal medicines where SIG members may have data or experiences to share. Since its inception, the H\&TMs SIG lead has compiled and sent email updates to SIG members on an approximately quarterly basis; teleconferences, also quarterly, were initiated in 2020. The SIG also meets annually, where possible, at the annual ISoP conference. The purpose of all these communications is to network, share information, stimulate debate, and possibly lead to the development of new project ideas.

The main focus of the SIG is on herbal medicines, since products based on herbal ingredients are among the most commonly used NHPs, and herbal substances are common ingredients in many traditional medicines. However, this does not exclude other types of ingredients included in traditional medicines and other NHPs.

The key objectives of the SIG are as follows:

- To discuss issues in H\&TMs safety and pharmacovigilance and work collaboratively toward finding solutions

- To raise awareness of issues in H\&TMs safety and pharmacovigilance among relevant organizations, including 
those representing patient groups, healthcare providers, medicines information providers, media and others

- To serve as a conduit for ISoP members wishing to initiate or be involved with collaborative research or other projects of relevance to the H\&TMs area.

The H\&TMs SIG aims to both be strategic in its outlook and have the flexibility to respond swiftly to emerging situations or needs. Against this background, and in line with the H\&TMs SIG's aims and objectives, a key goal is to achieve impactful outputs, in the form of journal articles, conference presentations, and so forth. Already, a subgroup of the H\&TMs SIG has worked collaboratively on a descriptive analysis of reports in VigiBase, the WHO global database of individual case safety reports, relating to hepatotoxicity associated with herbal medicines. A paper from this work has been published [18].

\section{Towards Resolving Challenges in Pharmacovigilance for H\&TMs}

There are numerous issues relating to pharmacovigilance for H\&TMs, and these have been comprehensively discussed in the literature $[15,19,20]$ and at an international conference dedicated to this topic in 2006 (Pharmacovigilance of Herbal Medicines: Current State and Future Directions) organized by the author in concert with the Royal Pharmaceutical Society of Great Britain, and with ISoP and other distinguished scientific societies in pharmaceutical sciences and herbal medicines as partners [21].

However, progress toward overcoming challenges in pharmacovigilance for H\&TMs has been slow. Part of the work of the H\&TMs SIG will be to develop an "issues" agenda, determine what actions are needed and work collaboratively and creatively both within and outside ISoP to develop, implement and disseminate innovative solutions. Members are invited to propose and discuss other issues relating to H\&TMs they feel are of importance. One example of a fundamental issue in pharmacovigilance for H\&TMs and other NHPs is the difficulty in classifying and coding these products and preparations. The UMC Herbal ATC classification system is a useful framework, but it is not used universally, and potential remains to improve and standardize how herbal medicines and other NHPs are classified and coded internationally. The H\&TMs SIG is developing a workplan on this topic through which it hopes to progress practice in this area.

The ISoP H\&TMs SIG aims to liaise and work collaboratively with other ISoP SIGs and chapters working on relevant issues; indeed, some H\&TMs SIG members are also members of other ISoP SIGs, such as the Women's Medicines and Risk Communication SIGs. Likewise, the H\&TMs SIG is committed to creating productive relationships with other international organizations and learned societies to advance the field, and activity in this area is expected to increase as the SIG evolves and matures. Some members of the group are involved with research and other projects concerning herbal medicines and other NHPs, and this may present opportunities for other SIG members to work as collaborators on these projects.

Acknowledgements Deidre McCarthy and Mira Harrison-Woolrych conceived the idea for the series of articles of which this is one.

\section{Compliance with Ethical Standards}

Funding No sources of funding were used to prepare this manuscript.

Conflict of interest JB has had registration fees paid for ISoP conferences in recognition of her roles as an invited member of the Scientific Organising Committee and/or invited chair of the herbal medicines session at those ISoP conferences. JB is a co-author of a textbook on pharmacognosy and phytotherapy and receives royalties in respect of that publication from Elsevier.

Ethics approval Not applicable.

Consent to participate Not applicable.

Consent to publish Not applicable.

Availability of data and material Not applicable.

Code availability Not applicable.

\section{References}

1. Eisenberg DM, Kessler RC, Foster C, Norlock FE, Calkins DR, Delbanco TL. Unconventional medicine in the United States: prevalence, costs, and patterns of use. N Engl J Med. 1993;328(4):246-52. https://doi.org/10.1056/NEJM19930128328 0406 .

2. Eisenberg DM, Davis RB, Ettner SL, Appel S, Wilkey S, Van Rompay M, et al. Trends in alternative medicine use in the United States, 1990-1997: results of a follow-up national survey. JAMA. 1998;280(18):1569-75. https://doi.org/10.1001/ jama.280.18.1569.

3. MacLennan AH, Myers SP, Taylor AW. The continuing use of complementary and alternative medicine in South Australia: costs and beliefs in 2004. Med J Aust. 2006;184(1):27-31.

4. Clarke TC, Black LI, Stussman BJ, Barnes PM, Nahin RL. Trends in the use of complementary health approaches among adults: United States, 2002-2012. Natl Health Stat Rep. 2015;79:1-16.

5. Morgan TK, Williamson M, Pirotta M, Stewart K, Myers SP, Barnes J. A national census of medicines use: a 24-hour snapshot of Australians aged 50 years and older. Med J Aust. 2012;196(1):50-3. https://doi.org/10.5694/mja11.10698.

6. Steel A, McIntyre E, Harnett J, Foley H, Adams J, Sibbritt D, et al. Complementary medicine use in the Australian population: results of a nationally-representative cross-sectional survey. Sci Rep. 2018;8(1):17325. https://doi.org/10.1038/s41598-018-35508 $-\mathrm{y}$. 
7. Bacon CJ, Bolland MJ, Ames RW, Siu AT, Mason BH, Horne AM, et al. Prevalent dietary supplement use in older New Zealand men. N Z Med J. 2011;124(1337):55-62.

8. Chrystal K, Allan S, Forgeson G, Isaacs R. The use of complementary/alternative medicine by cancer patients in a New Zealand regional cancer treatment centre. N Z Med J. 2003;116(1168):U296.

9. Smith T, Gillespie M, Eckl V, Knepper J, Reynolds CM. Herbal supplement sales in US increase by $9.4 \%$ in 2018 . HerbalGram J Am Bot Council. 2019;123:62-73.

10. Gardiner P, Graham RE, Legedza AT, Eisenberg DM, Phillips RS. Factors associated with dietary supplement use among prescription medication users. Arch Intern Med. 2006;166(18):1968-74. https://doi.org/10.1001/archinte.166.18.1968.

11. World Health Organisation. WHO traditional medicine strategy: 2014-2023. World Health Organisation, Geneva. 2013. https:// www.who.int/medicines/publications/traditional/trm_strategy 14 23/en/. Accessed 2 Mar 2020.

12. Betz J, Anderson L, Avigan M, Barnes J, Farnsworth N, Gerdén B, et al. Black Cohosh: considerations of safety and benefit. Nutr Today. 2009;44:155-62. https://doi.org/10.1097/NT.0b013e3181 af63f9.

13. Mazzanti G, Di Sotto A, Vitalone A. Hepatotoxicity of green tea: an update. Arch Toxicol. 2015;89(8):1175-91. https://doi. org/10.1007/s00204-015-1521-x.

14. Savage RL, Hill GR, Barnes J, Kenyon SH, Tatley MV. Suspected hepatotoxicity with a supercritical carbon dioxide extract of Artemisia аппиа in grapeseed oil used in New Zealand. Front Pharmacol. 2019;10:1448. https://doi.org/10.3389/fphar .2019.01448.

15. World Health Organisation. WHO guidelines on safety monitoring of herbal medicines in pharmacovigilance systems 2004.

16. The Herbal Anatomical Therapeutic Chemical Classification System. Uppsala Monitoring Centre. 2019. https://www.who-umc. org/whodrug/whodrug-portfolio/whodrug-global/herbal-atc. Accessed 2 Mar 2020.

17. Kelly WN, Arellano FM, Barnes J, Bergman U, Edwards IR, Fernandez AM, et al. Guidelines for submitting adverse event reports for publication. Pharmacoepidemiol Drug Saf. 2007;16(5):581-7. https://doi.org/10.1002/pds.1399.

18. van Hunsel F, van de Koppel S, Skalli S, Kuemmerle A, Teng L, Wang JB, Barnes J. Analysis of hepatobiliary disorder reports associated with the use of herbal medicines in the global suspected ADR database vigibase. Front Pharmacol. 2019;10:1326. https://doi.org/10.3389/fphar.2019.01326.

19. De Smet PAGM. An introduction to herbal pharmacovigilance. In: De Smet PAGM, Keller K, Hansel R, Chandler R, editors. Adverse effects of herbal drugs. Berlin: Springer; 1997.

20. Barnes J. Pharmacovigilance of herbal medicines : a UK perspective. Drug Saf. 2003;26(12):829-51. https://doi. org/10.2165/00002018-200326120-00001.

21. Pharmacovigilance of Herbal Medicines. Current state and future directions. Drug Saf. 2006;29(4):341-70. https://doi. org/10.2165/00002018-200629040-00005. 